\title{
Patterns of online repeat victimisation and implications for crime prevention
}

\author{
Author information \\ Sara Giro Correia, Lecturer in Cyber Threats, Swansea University
}

\begin{abstract}
This paper explores the characteristics of repeat victimisation (RV) in relation to fraud and computer misuse (F\&CM) crimes recorded in Wales, United Kingdom (UK). The wider study included mixed-methods analysis of a sample of cases $(\mathrm{n}=10,001)$ reported by individuals in Wales, over a period of two years (ending in September 2016). In this paper, key results from the quantitative part of this study concerning RV are presented. This paper contributes to an empirically grounded understanding RV with respect to F\&CM and its insights are of direct relevance to theoretical understandings of victimisation and the formulation of interventions within the 'Protect' strand of policing in the UK. It suggests that older age is associated with $\mathrm{RV}$ for these crime types, that a repeat report is likely to be of the same general type as the crime which preceded it and that interventions to protect individuals from being re-victimised are best targeted within two weeks to one month of the first report. The paper also highlights the extent to which RV analysis is constrained by the rules which shape crime recording and identifies avenues for improvement of data collection and further research. Furthermore, it suggests the need to develop a framework of F\&CM vulnerability which goes beyond risk of re-victimisation and better accounts for and enables a response to victims' wider support needs.
\end{abstract}

\section{Part I - Introduction}

The significance of Fraud and Computer Misuse (F\&CM) victimisation has been highlighted in the UK since 2015 when, for the first time, these crime types were included in the yearly crime estimates produced by the Office for National Statistics (ONS), based on the Crime Survey for England and Wales (CSEW) [1]. Recent estimates indicate that there were approximately 4.6 million incidents of Fraud and 876,000 incidents of Computer Misuse in the year ending March 2020, bringing the overall crime estimate from approximately 5.7 to without F\&CM to 10.2 million estimated crimes [2]. While the same data suggests that only a small proportion of these crimes are estimated to be reported to the police $(8 \%$ of fraud and $2 \%$ of $\mathrm{CM}$ ), the total volume of F\&CM recorded has increased enormously in the past few years, providing a large and rich sample for analysis. Alongside these figures, the UK government have committed considerable sums to cyber security - $£ 1.9$ billion between 2016 and 2021 [3]. As the UK re-considers their cyber-security strategy post-2021, it is timely to consider understandings of victimisation in relation to $\mathrm{F} \& \mathrm{CM}$.

At the same time, the processes by which victims report F\&CM and the ways in which victim services are delivered have changed significantly since the UK's Coalition Government (20102015). Firstly, the reporting of F\&CM has improved significantly with the introduction of the 
National Reporting Centre Action Fraud (AF). Its introduction mirrored equivalent systems in the USA and Canada and had been recommended by The Fraud Review, [4] as well as academic experts [5, 6]. Following its rollout in 2013, individuals in report F\&CM by either contacting the AF call centre or using the online reporting tool, resulting in the volume of frauds recorded increasing by over 160\% between 2011 and 2013 [2]. Secondly, victim support services have been decentralised, becoming (or reverting to) local delivery, with the addition of competitive bidding for service providers wishing to deliver those services, funded through the democratically elected Office of the Police and Crime Commissioners (PCCs). [7] However, the response received by F\&CM victims has come under some scrutiny following several AF institutional crisis [8,9] and it has been noted that there is considerable 'attrition' within the criminal justice system (CJS) [10]. As such, only a small proportion of calls received by AF are labelled crimes ('crimed'), an even lesser number are reviewed for investigation, of which fewer reach the courts. As such, most victims receive no meaningful response from the CJS. To a large extent, this is a result of decreasing budgets resulting in other crime types, especially violent crimes, being prioritised. However, F\&CM has severe impacts on a minority of victims [11] and for those victims, a different kind of response is necessary, even if a crime investigation is not feasible. Furthermore, the Code of Practice for Victims of Crime [12] calls for vulnerable and repeat victims to be identified and offered adequate support. Despite this, there is limited research into repeat victims of F\&CM [13] and inconsistent definitions of vulnerability are used by law enforcement and other agencies [14].

As such, the wider study employed a mixed-methods approach to explore F\&CM victimisation, with a focus on identifying patterns of RV and constructions of vulnerability. It did so through the analysis of a two-year sample of crime reports made by individuals in Wales $(n=10,001$, reference period ending September 2016), linked through a mix of deterministic and probabilistic methods to identify reports within that sample which pertained to the same individual victim. The study also employed qualitative Thematic Analysis [15] to identify how victim vulnerability is constructed within crime reports. In this paper however, the focus is the key RV patterns identified through bi-variate quantitative analysis. These patterns provide an empirical basis for understanding RV with respect to $\mathrm{F} \& \mathrm{CM}$ and are of direct relevance to the formulation of interventions within the 'Protect' strand of policing. Unlike the traditional 'Pursue' type activity of investigating crimes to enable prosecutions, 'Protect' is focused on increasing protection for those who are at risk of (further) victimisation. ${ }^{1}$ It is argued that responding to $\mathrm{RV}$ should be prioritised as a broader crime prevention strategy for $\mathrm{F} \& \mathrm{CM}$, especially where there is a focus on meeting the needs of vulnerable victims.

\section{Part II - Context}

\section{Why Repeat Victimisation Matters}

Early work into RV across all crime types highlighted that as much as $14 \%$ of the population were repeat victims and that they reported $70.9 \%$ of the incidents recorded on the then British

\footnotetext{
${ }^{1} \mathrm{~F} \& \mathrm{CM}$ policing strategy in the UK has four strands, following the 'four Ps' approach which originated from the field of counter-terrorism policing: 'Pursue', 'Prevent', 'Protect' and 'Prepare'. In addition to 'Pursue' and 'Protect' already described, 'Prevent' is concerned with preventing people from engaging in F\&CM and includes raising awareness of the consequences of offending and, in the case of $\mathrm{CM}$, initiatives to ensure talented individuals are diverted towards legal/ethical 'hacking'. 'Prepare' strand is focused on improving resilience in order to reduce the impact of F\&CM in the future.
} 
Crime Survey [16]. Furthermore, it has been noted that the average number of crimes experienced by the top 10\% most victimised households has increased from 57\% in 1994 to $72 \%$ in 2012, despite the overall drop since the mid 1990s [17]. RV has since been examined across a variety of crime types including racially motivated crime [18], domestic violence [19] and domestic burglary [20,21] but remains under-studied with respect to F\&CM [13]. This literature shows that patterns of RV reveal important information for the development of crime prevention initiatives. This is because being a victim is, "for whatever [...] combination of reasons, a good predictor of swift future victimisation" [22]. Furthermore, analysis indicates that RV does not occur randomly [23-25] and it is associated with specific demographic characteristics $[17,26]$. As such, in the context of limited resources, crime prevention is well targeted at those who have already become victims.

Despite the scholarship, policy markers' interest in understanding RV has declined since its peak in the 1990s [13]. Furthermore, while the insights from the previously mentioned scholarship are extremely useful, crime prevention must be tailored to crime types, victims' circumstances and available local resources. However, little research has been carried out into the prevalence and circumstances surrounding repeat victims of F\&CM. With some notable exceptions [27, 28], it has been noted that the study of cybercrime "through a repeat victimisation lens is overdue" [13]. At the same time, recent work has called for the reconceptualisation of 'the victim' in relation to $\mathrm{CM}$ crimes and other crimes with significant online/offline dynamics which challenges the idea of a victim as a single agent, victimisation as a single event and dichotomies such as online/offline and victim/offender [29]. As such, exploring RV will also contribute to these ongoing theoretical debates.

\section{Defining and Measuring Repeat Victimisation}

Terms used to refer to the experience of being a crime victim more than once have included "revictimisation, multiple victimisation, repeat victimisation, multi-victimisation, repetitive victimisation and recidivist victimisation" [22]. The Crime Survey for England and Wales (CSEW) defines a repeat victim as someone who was the victim of the same crime type more than once (within crime type victim), in the previous 12 months [30]. This is distinguished from multiple victimisation which is where a victim experiences more than one crime in the previous 12 months, regardless of crime type (across crime type victim). As this paper is limited to an analysis of F\&CM, the term repeat victim is used to include not only victims who reported more than one fraud or more than one computer misuse crime, but also those who reported a mix of F\&CM within the reference period.

While there is little research into repeat victims of F\&CM, CSEW estimates indicated that $12 \%$ of Fraud and 11\% of CM victims were repeat victims in the year ending March 2020 [31]. The extent of RV (within crime type) can also be gauged from the ratio of incidence to prevalence rates calculated based on the CSEW. The incidence rate (IR) is the estimated average number of incidents per 1000 respondents, while the prevalence rate (PR) counts victims and it is the estimated percentage of respondents who were victimised [32]. The measure of crime concentration (CC) is the ratio between incidence and prevalence and counts crimes per victim, i.e. the average number of victimisations per victim [33]. For most crime types, the effect of repeat and multiple victimisation means that incidence will be greater than prevalence and thus 
concentration will be greater than one. ${ }^{2} \mathrm{IR}, \mathrm{PR}$ and $\mathrm{CC}$ rates for a number of crime groups including F\&CM are shown in Table I.

\begin{tabular}{|c|c|c|c|}
\hline Crime Category & IR & PR & $\mathbf{C C}$ \\
\hline Theft from the person & 0.88 & 0.84 & 1.05 \\
\hline Robbery & 0.32 & 0.30 & 1.07 \\
\hline Other theft of personal property & 1.44 & 1.32 & 1.09 \\
\hline Fraud & 8.08 & 6.94 & 1.17 \\
\hline$C M$ & 2.14 & 1.82 & 1.18 \\
\hline Fraud \& $C M$ & 10.23 & 8.48 & 1.21 \\
\hline Violence & 2.74 & 1.76 & 1.55 \\
\hline
\end{tabular}

Table I - Incidence Rates (IR), Prevalence Rates (PR) and Crime Concentration (CC) in year ending September 2019. Source: Crime Survey for England and Wales (CSEW).

As Table I shows, whereas the concentration of F\&CM offences is lower than violent crimes, it is higher than more comparable offences such as theft from the person and theft of personal property. This is indicative of the need to empirically explore RV with respect to F\&CM and understand how it may impact on understandings of victimisation and crime prevention strategies. First however, to generate research questions and hypotheses with respect to F\&CM repeat victims, known patterns of RV across other crime types were examined. These are briefly discussed below.

\section{Patterns of Repeat Victimisation}

As noted above, previous research into RV has established its importance in relation to crime prevention. Several key insights are worth noting. Firstly, studies suggest that a large proportion of crime was experienced by a small number of repeat victims $[16,34,35]$. This in turn suggests that where crime prevention strategies are designed to reduce RV, they will "prevent a large proportion of all offences from being committed" [16]. Furthermore, failed attempts to fit the distribution of RV to variations of the Poisson model suggest that RV does not happen by chance $[16,23,36,37]$ and is associated with specific demographic characteristics $[17,26]$. Generally, the characteristics that distinguish repeat from one-time victims are the same ones that distinguish victims from non-victims. For example, previous research has indicated that just as females are significantly more likely to be one-time victims of domestic abuse, the same is true of repeat victims [38]. CSEW figures for the year ending March 2019 show that the profile of F\&CM victims is in some ways similar to other crime types (typical victims of $\mathrm{CM}$ are young, males), but in others considerably different to that of

\footnotetext{
${ }^{2}$ Prevalence should be greater for crimes with more than one victim. Fraud (particularly online fraud) is often a one to many crime. However, due to the way CSEW data is collected based on household and individuals, along with the application of Home Office Counting Rules to police recoded crime, this is unlikely to be identified through either.
} 
other crimes (higher socio-economic status and no differences across ethnic backgrounds) [39]. Furthermore, a representative study of the UK population indicated that $26 \%$ of fraud victims became repeatedly victimised in their lifetime [40] and a more recent study of victims and nonvictims found $45 \%$ of victims were repeat victims [27]. However, there is little to no research examining the profile of one-time vis-à-vis repeat victims of F\&CM.

Furthermore, patterns of RV vary between crime types such that for example, victims of domestic abuse are more likely to be re-victimised than victims of other crime types [41]. This may be because those individuals were more vulnerable in the first place, or because being a victim increased their vulnerability to further victimisation. In other words, RV has been conceptualised as both a 'flag' for vulnerability or as 'boosting' vulnerability to victimisation $[13,42]$. In RV literature, greater 'vulnerability' appears to be conceptualised in narrow sense as equivalent to a greater probability of victimisation. However, identifying victims as 'vulnerable' based solely on demographic characteristics can be divisive, says little about how RV occurs and would yield too many false positives to be of practical use. In contrast, identifying repeat victims is a narrower and more precise way of determining relative vulnerability to victimisation, which is the focus of this paper. At the same time, analysing the sequence of RV events will illuminate the mechanisms of victimisation itself and is an area for further research.

Another insight from previous research is the association between high rates of RV ('hot dots') and geographical concentrations of crime ('hot spots') [43]. According to this evidence, what distinguishes high crime areas is not that more individuals are victims of crime, but that more victims of crime are repeatedly victimised. As such, protecting victims from RV will coincide with areas where crime is highest and result in crime reduction. This has led to the growth in research into 'near repeats', predicting where crime will take place next, based on where it has previously taken place geographically. However, given the significant online component of crimes such as F\&CM, this spatial element may be irrelevant. Even if crimes involve both online and offline methods (e.g. a victim is cold-called and socially engineered into providing information which results in the takeover of their online banking), there are very limited ways in which the physical environment determines victim selection - other than, perhaps, having a landline phone and/or access to Internet services (services which are, for the most part, available throughout England and Wales). As such, RV is likely a more useful metric of crime concentration than near-repeats to determine where crime prevention resources should be deployed [13]. Finally, RV has been shown to happen relatively soon after the first victimisation for repeat crimes of burglary and property crime [44, 45], racial attacks [18] and domestic violence [16]. Similar findings also indicate that repeats happen relatively swiftly with respect to Computer Misuse offences [46]. This suggests the risk of RV is highest immediately after victimisation.

\section{Part III - Method}

\section{Sample}

The data sampled for quantitative analysis included all crime reports made to AF by victims within the four Welsh police forces (Dyfed/Powys, Gwent, North Wales \& South Wales), between $1^{\text {st }}$ October 2014 and $30^{\text {th }}$ September 2016 (the reference period). Once duplicates were removed $(n=147)$, the sample for analysis became $n=17,049$ cases. Of these, $n=11,844$ were identified as pertaining to individual victims (rather than public entitites, businesses or other corporate entities). This is equivalent to all reports made within these forces over a period 
of two years, which were subsequently divided into eight three-month periods (i.e. four quarters per year). The sample start date was determined by what data was available to the Southern Wales Regional Organised Crime Unit (SW-ROCU). In addition, SW-ROCU and the author expected that by 2014 the quality of the AF data would have stabilised, following the rolling out of the service nationally in April 2013. Finally, the researcher requested a two-year sample ending in September, as this allowed for a comparison between years and with CSEW estimates for the same period. However, due to the availability of personal identifiers required for linkage, only individual reports made within three out of the four police forces (Dyfed/Powys, Gwent and the South Wales) were used for the RV analysis $(\mathrm{n}=10,001)$.

\section{Collection Method}

The reported crime dataset was collated by the researcher from the monthly extracts of crimes reported to AF, as uploaded by the National Fraud Intelligence Bureau (NFIB) onto the police's NicheRMS system (also monthly) and extracted by SW-ROCU for the purposes of this study. ${ }^{3}$ As such, the sampled data provides a snapshot in time, of the new reports at the end of each month, made within the reference period. The data was provided to the researcher in four separate batches between August 2015 and August 2017. The first batch of data included crimes reported by victims in Gwent, Dyfed Powys and South Wales between June 2014 and November 2015. The second batch added crimes reported up until February 2016 for the same forces. The third batch included data for reports in North Wales for the equivalent period of June 2014 to February 2016. Finally, the fourth batch included reports for all four Welsh police forces between February and September 2016.

The research partners sponsored the researcher to obtain the required level of security clearance and the data was accessed and processed under strict controls, within secure police premises. These unique data-access arrangements allowed for the application of a de-duplication data linkage method prior to the anonymisation of the dataset. This de-duplicative linkage was key to identifying repeat victims among the reported incidents. Most of the analysis however happened after the data had been fully anonymised and securely transported to the University.

The data collected is thus classed as administrative linked data, i.e. data originally collected by AF "expressly for the purpose of conducting administrative tasks and meeting [its] administrative responsibilities" [48], which was then further processed by the author to meet the needs of the research. The limitations of using this type of administrative data, i.e. police reported crime (PRC), in research, have been discussed at length elsewhere and often stem from the mis-alignment of the purpose for which the data was originally collected (the administration of justice), the collection methods used and the concepts/units measured on one hand, and the aims of the research project $[5,49]$. By far the greatest limitations of AF data in the context of this research relates to the under-reporting of F\&CM, the impacts of the Home Office Counting Rules (HOCR) on the measurement of RV and the impact of external events on the data collection by AF. Each of these will be discussed throughout this paper. In addition, there were methodological constrains associated with the linkage method used to identify reports by the same individual victim (see below).

\footnotetext{
3 NicheRMS is an operational platform provided by Niche Technology Incorporated, a private Canadian corporation based in Winnipeg, Manitoba. NicheRMS is used by police services in the United States, Canada, the United Kingdom, and Australia [47] Niche Techonology. "Who We Serve." https://nicherms.com/whowe-serve/ (accessed 4 June 2019..
} 
Despite these limitations however, there are considerable benefits in making use of the richness of AF data. While under-reported, the volume of crimes which are recorded by AF are sufficient for statistical analysis and the insights they provide most relevant where the focus is the current CJS response to known victims. Furthermore, as it will be seen below, the linking of AF individual records allowed for the observation of RV patterns which cross-sectional survey methodologies are ill suited to make visible [50]. Finally, as the discussion in this paper highlights, this research aimed in part, to understand the limitations of the data collected by AF and make recommendations for improvements which may better enable police forces to meet victims' needs. As such, the limitations of the dataset with respect to identifying RV was a key point of interest for investigation.

\section{Data Analysis}

In this paper, data pertaining to crime reports made within three Welsh police forces (including Dyfed/Powys, Gwent and South Wales $)^{4}$ were linked using a combination of deterministic and probabilistic data linkage, using the $\mathrm{R}$ package RecordLinkage [51, 52]. This method allowed the author to identify reports made by the same victim within the reference period. The quality of the linkage was tested using two commonly used linkage quality metrics, precision and recall (or sensitivity) [53], based on the clerical review of a sample of 100 pairs of matches. Although both precision and recall were estimated at $100 \%$, the linkage method was optimised to minimise false-positive matches and thus may have yielded false-negatives (missed matches) which were not captured in the reviewed sub-sample. Following the data linkage, bivariate statistical analysis was used to explore patterns of RV. Measures of statistical significance and effect size are provided throughout.

\section{Part IV - Results}

\section{Extent of Repeat Victimisation}

Of a total of $\mathrm{n}=10,001$ incidents reported by individual victims in the three Welsh police forces considered for this analysis, a combination of exact and probabilistic linkage techniques was used to identify crimes reported by the same individual. This resulted in 350 individual repeat victims being identified, who reported 787 crimes between them. This data indicates that around $8 \%$ of crimes reported by individual victims (and recorded) within the reference period were attributable to repeat victims, a somewhat lower figure than expected based on the aforementioned CSEW estimates (Figure 1).

\footnotetext{
${ }^{4}$ Reports from North Wales were excluded from the repeat victim analysis on the basis that the considerable level of missing values within linkage variables skewed the results of the linkage.
} 


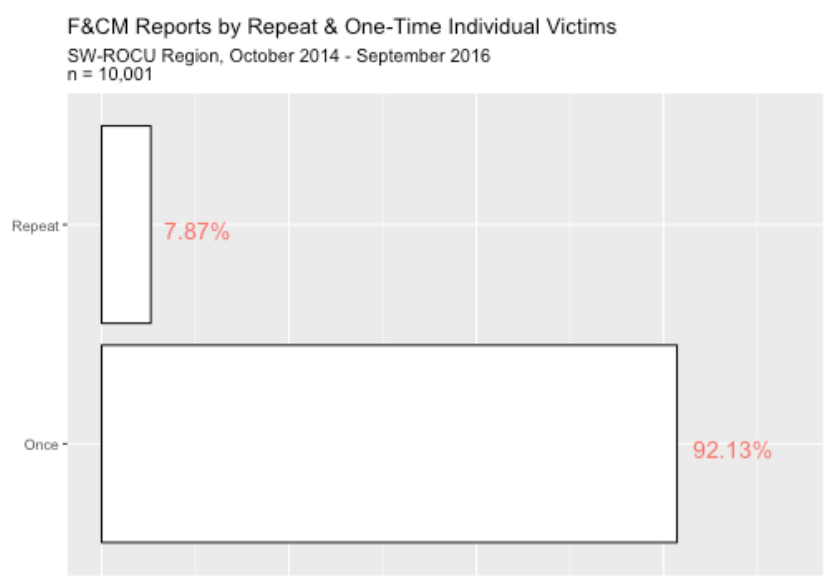

Figure 1

However, for three main reasons, this is likely an underestimate. Firstly, the limitations of the data linkage methodology may have conditioned the number of repeats that could be identified. Secondly, because the sample is limited to a two-year period, it is both left and right-censored. In other words, both earlier and later reports may be repeats of reports that were out of scope and thus not identified as repeats. Finally, the recording of incidents is shaped by the Home Office Counting Rules (HOCR) [54]. The application of these rules means that in some cases, incidents that happened over several days will be registered as one incident (e.g. an advance fee fraud where the victim has sent money to the fraudster several times, over a period of time). This is contrasted with crime types such as the hacking of personal accounts, where each account hacked will be registered as a separate crime, even if the incidents happened or were reported on the same day.

The impact of the counting rules may therefore also explain the different levels of RV found when comparing Fraud to CM. As illustrated in Table II, the extent of RV varied across the two crime groups, with a greater proportion of repeat victims among those who reported CM crimes. Approximately 3\% of fraud victims reported $7 \%$ of recorded frauds. For CM, approximately $6 \%$ of victims reported $15 \%$ of crimes.

\begin{tabular}{|c|c|c|c|c|c|c|}
\hline nreports & $n($ fraud $)$ & $\begin{array}{l}\text { Incident } \\
\text { prop(fraud) }\end{array}$ & $\begin{array}{l}\text { Victim } \\
\operatorname{prop}(\text { fraud })\end{array}$ & $n(C M)$ & $\begin{array}{l}\text { Incident } \\
\text { prop }(C M)\end{array}$ & $\begin{array}{l}\text { Victim } \\
\operatorname{prop}(C M)\end{array}$ \\
\hline 1 & 8527 & 92.72 & 96.53 & 687 & 85.45 & 93.99 \\
\hline 2 & 533 & 5.8 & 3.02 & 59 & 7.34 & 4.04 \\
\hline 3 & 88 & 0.96 & 0.33 & 20 & 2.49 & 0.91 \\
\hline 4 & 23 & 0.25 & 0.07 & 9 & 1.12 & 0.31 \\
\hline 5 & 5 & 0.05 & 0.01 & 20 & 2.49 & 0.55 \\
\hline 6 & 21 & 0.23 & 0.04 & 9 & 1.12 & 0.21 \\
\hline $\begin{array}{l}\text { total } \\
(n>1)\end{array}$ & 670 & 7.29 & 3.47 & 117 & 14.56 & 6.02 \\
\hline
\end{tabular}

Table II

The statistical significance of the difference between the levels of RV reported among CM and Fraud victims was significant as confirmed by a Chi-squared test $\left(\chi^{2}(1)=52.86, p<0.01\right)$. In addition, the odds ratio was computed indicating that the odds of a victim of $\mathrm{CM}$ being a repeat 
victim are approximately two times higher than those of a Fraud victim (2.17), representing a small to medium effect size [55]. This highlights the importance of understanding the data collection processes in detail where administrative data is re-purposed for research. While this significant suggests a difference between F\&CM, it is possible that this is caused by the application of HOCR, rather than a higher rate of RV for CM crimes.

Alongside the above, this data indicates that there is a significant difference between the number of repeat versus one-time crime reports across the three Welsh forces considered $\left(\chi^{2}\right.$ $(2)=16.26, p<0.01)$. The standardised residuals indicate that this difference is driven by reports in Dyfed/Powys being significantly more likely to be made by repeat than one-time victims and conversely, those reported in South Wales being significantly more likely to be made by one-time than repeat victims $(\mathrm{p}<0.01)$ (Table III). However, the effect size based on Cramér's $V(0.04)$ is negligible [56]. As such, further research is needed to fully understand differences in RV across these Welsh forces. Nonetheless, it is clear that measuring RV can identify areas where interventions to reduced RV are most needed, were this analysis to be extended to all police forces in England and Wales.

\begin{tabular}{l|lll}
\multicolumn{1}{l}{ Force } & Victim Type & $N$ & St. Residuals \\
\hline Dyfed/Powys & Once & 2210 & $-3.60^{* *}$ \\
& Repeat & 234 & $3.60 * *$ \\
Gwent & Once & 2200 & -0.57 \\
& Repeat & 195 & 0.57 \\
South Wales & Once & 4804 & $3.58^{* *}$ \\
& Repeat & 358 & $-3.58^{* *}$
\end{tabular}

Table III - Number of Repeat and One-Time Reports by Force along with Chi-squared standardised residuals. ** indicates statistical significance at $\mathbf{p}<0.01$.

\section{Repeat Victims Characteristics}

\section{Demographic Characteristics}

The data were analysed to establish whether repeat victims' characteristics differed significantly from one-time victims with respect to variables of criminological interest including gender, ethnicity and age. This analysis revealed that more incidents were reported by male victims were repeats when compared to incidents reported by female victims (Figure $2)$. A chi-squared test $\left(\chi^{2}(1)=14.05 \mathrm{p}<0.01\right.$, ) and Cramér's $V(0.03)$ suggest a statistically significant difference, but a negligible effect size. This negligible effect is further illustrated by the odds ratio as the odds of an incident being reported by male repeat victim are only 1.33 times higher than those of an incident reported by a female victim. Furthermore, no significant difference was found between one-time and repeat victims in terms of ethnicity $\left(\chi^{2}(1)=0.067\right.$, $\mathrm{p}>0.5)$. However, this result may be skewed by the overwhelming number of missing values for the ethnicity variable ( $34 \%$ missing). In addition, due to the small number of cases in most categories (apart from 'White') a binary White or Black and Minority Ethnic (BME) had to be used so as to not violate statistical assumptions. 


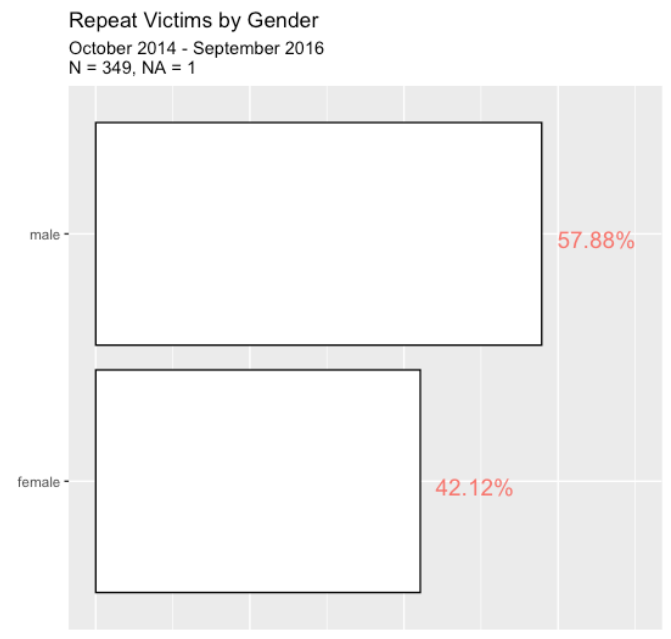

Figure 2

The largest effect with respect to victim characteristics found was victims' age, with the typical repeat victim being older than one-time victims. This is visible on the age histograms of repeat and non-repeat victims, with fewer reports from the younger victims in the repeat victim group (Figure 3). In addition, both the mean and the median age at the time of reporting are higher for repeat (median age 57, mean age 53.6) than one-time victims (median age 50, mean age 49.93). The significance of the difference between the mean age between these groups was confirmed with a significant Wilcoxon rank-sum $(\mathrm{W}=3197004, \mathrm{p}<0.001)$.

Histogram of Age

October 2014 - September 2016

$\mathrm{N}=8288, \mathrm{NA}=1713$

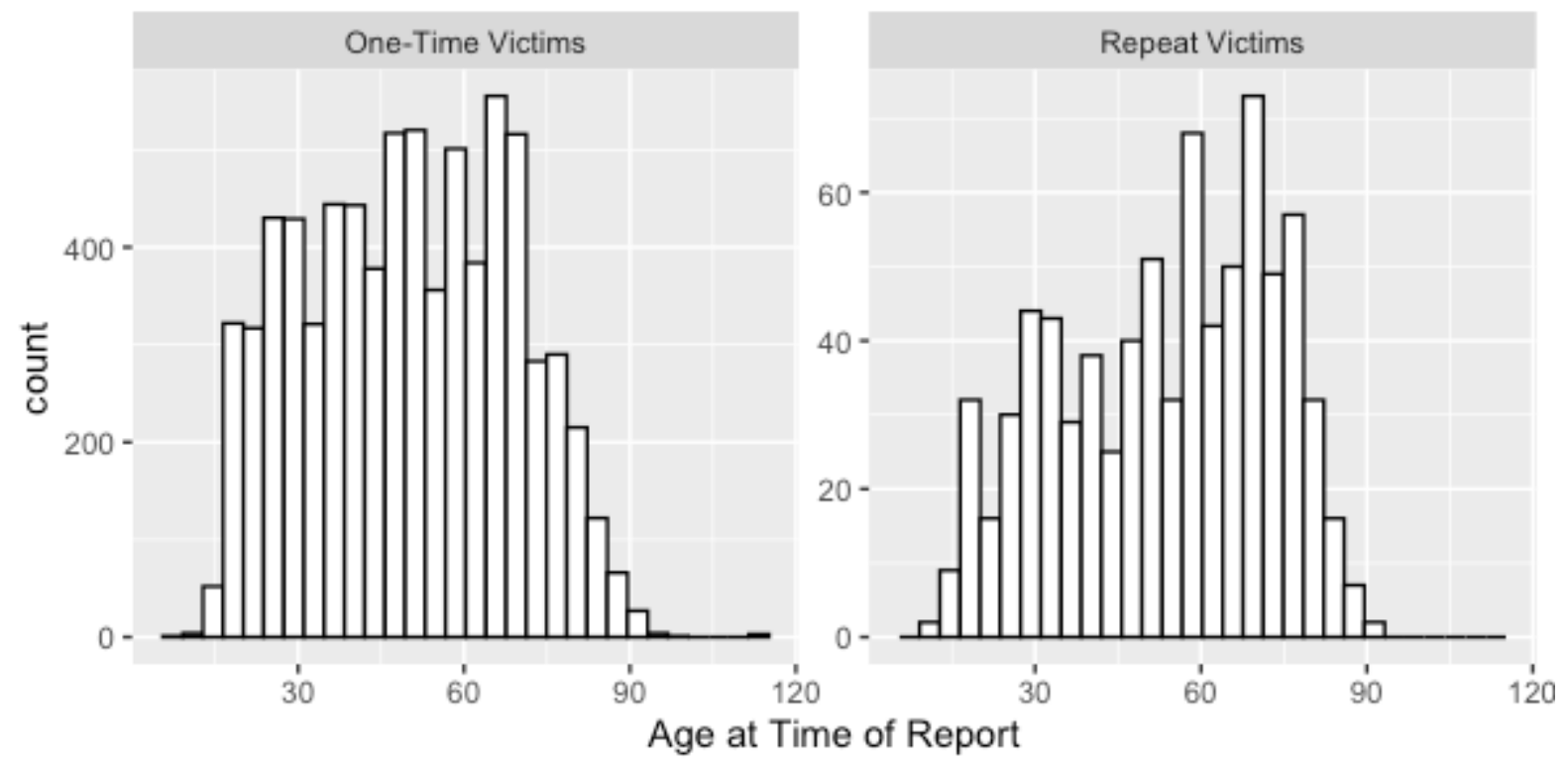

Figure 3

It is possible that the linkage methodology introduced a bias towards linking for older victims, thus over-representing older repeat victims. However, date of birth (DOB) was a key component of the linkage method and there were instances of proxy reports on behalf of older victims (by family and friends). If anything, this should have led to increased inaccuracy and missing values for the DOB provided for older victims. As such, these findings are indicative 
of overlap between RV and older age, i.e. a greater risk of or vulnerability to (re-)victimisation for older victims. However, qualitative analysis is required in order to better understand how and why older victims may be more vulnerable to RV. Furthermore, the negative impacts of F\&CM victimisation, particularly on older victims, are varied and may affect the victim's wellbeing, family relationships and cause indirect financial losses [11, 57]. Such impacts may also be associated with factors beyond the crime itself, such as social isolation or economic disadvantage. Conceptualising vulnerability to extend beyond the direct harms of crime and the increased likelihood of (repeat) victimisation will be necessary to the provision of adequate victim support for some victims.

Finally, it had been hypothesized that cases flagged as having been reported by a "proxy" on behalf of the victim may be associated with RV and therefore greater vulnerability to victimisation. This hypothesis was formulated based on anecdotal evidence from practitioners that often friends and family reported on behalf of especially vulnerable individuals. These in turn, were expected to be significantly more likely to be repeatedly victimised. Within the overall sample, $10 \%$ of incidents were reported by proxy $(n=1,024)$. However, the data shows the opposite to the expected effect - a greater proportion of one-time victims $(11 \%)$ were flagged for a proxy report than repeat victims $(6 \%)$. This was a statistically significant difference, but the effect size negligible $\left(\chi^{2}(1)=13.58, \mathrm{p}<0.01\right.$, Cramér's $\left.V=0.04\right)$. This raises the possibility that practitioners' experience is indicative of proxy reports being associated with wider vulnerability factors, which are not captured by RV measures alone. Further research is required on this point.

\section{Time-Course of Repeat Victimisation}

Previous literature has highlighted the importance of the time-course of RV and its implications for crime prevention activities. As such, the time-course of RV was investigated with respect to this sample. As the sample spanned two years, a small number of cases linked across a period longer than one year would have skewed the analysis towards longer periods between events, particularly towards the end of the reference period. As such, the time-course analysis provided below is limited to consecutive reports within 12 months $(n=406)$, excluding that small minority of cases where the time difference was greater than 366 days $(n=31) .^{5}$

\section{Inter-report Time}

The first aspect investigated with respect to time-course was the distribution of the inter-report time - i.e. the distribution of the time elapsed between consecutive incidents. As shown in Figure 4, the distribution is concentrated at the lower end of the scale and the graph gives the appearance of an exponential decrease in the number of incidents as the time difference between them increases.

\footnotetext{
${ }^{5}$ The year was assumed to have a maximum of 366 days given that 2016 was a leap year. In addition, the time course analysis only counts the time difference between reports made by the same individual. As such, the first case of each series of reports by the same individual does not count, which results in NA $=350$ out of the 787 linked incidents.
} 


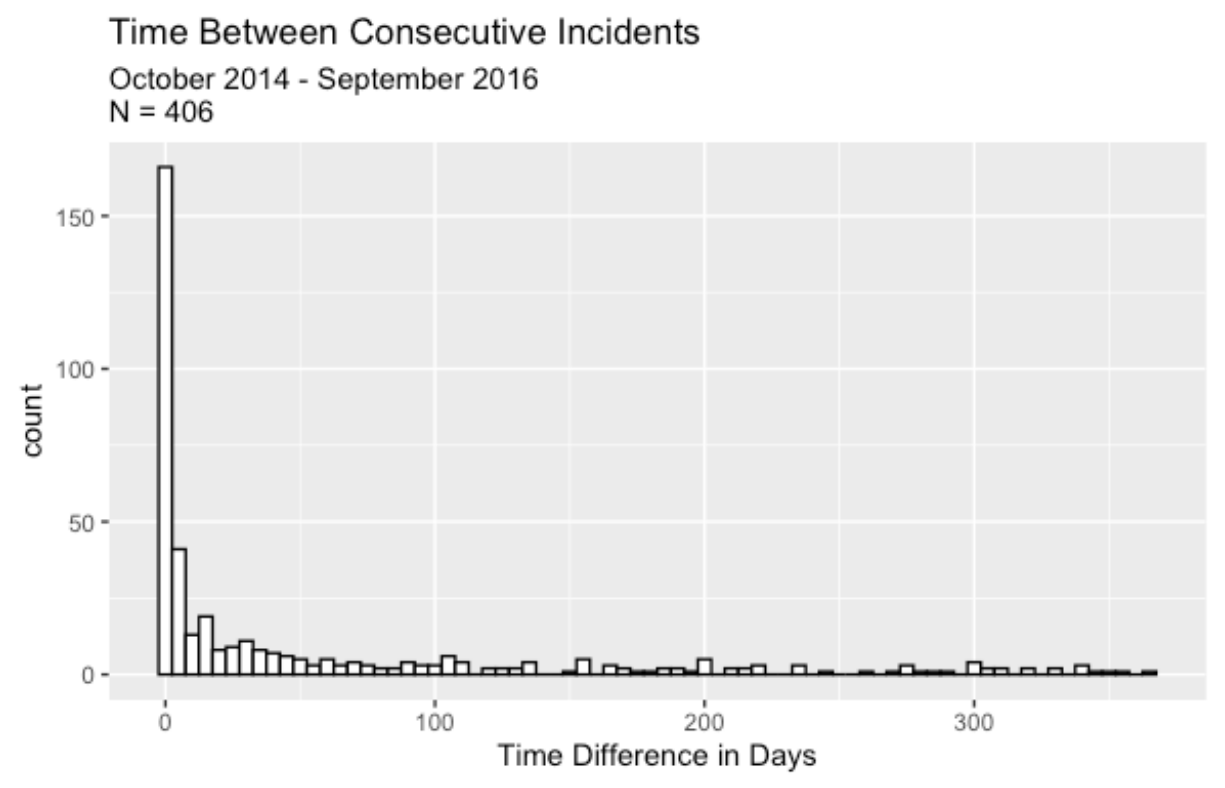

Figure 4

This is in line with previous research into repeat network attacks [46] although no equivalent research is available with respect to fraud. In addition, $15.5 \%$ of all linked (repeat) incidents were reported on the same day $(\mathrm{n}=122)$. How multiples instances reported on the same day are recorded however, depends on the Home Office Counting Rules for each specific category of F\&CM. In some cases, multiple same-day reports are recorded separately e.g. where multiple online accounts are hacked, one report per account is made. In others, arguably separate instances of victimisation are recorded as one crime e.g. multiple payments requested by the same fraudster over time. As shown in research into repeat victim referrals [58], this analysis highlights how crime recording practices have an impact on the identification and measurement of RV also for F\&CM crimes.

The exponential distribution of time differences (made starker by the number of same day reports) means that the median is a better representation of a typical time difference between reports than the mean. The overall mean difference between reports is 83 days and the median 12 days (excluding same day reports, the mean is 115 days and the median 40 days). In addition, the mean difference between the first and last report by individual repeat victims is 137 days and the median 49 days (excluding same day reports). As such, this data suggests that interventions aimed to protect victims from being re-victimised should ideally take place within two weeks to one month of the first report. Furthermore, on the one hand there is some indication that this tendency for a higher concentration of consecutive reports within the lower range of time differences seems to hold over time, when examined across each of the quarters of the two-year period under study. On the other hand, the data becomes considerably more dispersed in year two. This increased dispersion is observable in the mean and median time differences over time (Table IV).

\begin{tabular}{l|lllll}
\multicolumn{1}{l}{ year } & quarter & $\boldsymbol{n}$ & mean(diff) & median(diff) & $\max ($ diff) \\
\hline $\mathbf{2 0 1 4 - 2 0 1 5}$ & Q1 & 43 & 4.02 & 0 & 45 \\
& Q2 & 73 & 12.16 & 2 & 136 \\
& Q3 & 85 & 34.48 & 7 & 208 \\
& Q4 & 46 & 43.43 & 5 & 306
\end{tabular}




\begin{tabular}{l|lllcc} 
2015-2016 & Q1 & 23 & 134.22 & 122 & 338 \\
Q2 & 45 & 142.71 & 97 & 363 \\
Q3 & 36 & 81.61 & 25.5 & 357 \\
Q4 & 55 & 67.33 & 30 & 338
\end{tabular}

Table IV - Frequency, mean, median and maximum values for the time difference between consecutive reports, per quarter.

This effect is most likely caused by the left-censoring of the data - for the earlier periods, there is a shorter period available within which the previous event could have occurred. As such, there will be more first events in a series within the first quarter of the first year. In addition, a crises at AF between the last quarter of the first year and the first quarter of the second, had a considerable impact on the number of reports recorded. ${ }^{6}$ At the same time, right-censoring of the data might also contribute to the median peaks in the middle of the two-year sample period. As such, while this data is indicative of an exponential distribution of the time differences between reports, further (longitudinal) research is required to fully substantiate this claim.

\section{Number of Repeats}

There is mixed evidence with respect to the relationship between the number of RV reports and the time difference between reports. Table $\mathrm{V}$ gives the appearance of a general decrease in the mean time-difference between reports, particularly the number of reports is greater than five. In fact, a Kruskal-Wallis rank sum test confirmed that there was a statistically significant difference between the mean time difference grouped by number of reports made $\left(\chi_{2}(5)=\right.$ $1369.8 \mathrm{p}<0.01)$. However, using the $\mathrm{R}$ function pairwise.wilcox.test to calculate pairwise comparisons between group levels with corrections for multiple testing, it was concluded that only where nreports $=5$, is the mean time diff significantly different from the nreports groups 2 to $4(\mathrm{p}<0.05)$. Furthermore, the previously noted dispersal of the data suggests that differences in means between these groups may be of little practical consequence, as they do not capture the most typical values in the data. As such, while more evidence is needed, this analysis suggests that the number of repeat reports has little impact on the time-course of RV.

\begin{tabular}{l|lll}
\multicolumn{1}{l}{\begin{tabular}{l} 
nreports \\
\multicolumn{1}{l}{$\begin{array}{l}\text { Mean time } \\
\text { diff }\end{array}$}
\end{tabular}} & $\begin{array}{l}\text { Median time } \\
\text { diff }\end{array}$ & $\boldsymbol{n}$ \\
\hline $\mathbf{2}$ & 93 days & 35 days & 296 \\
4 & 77 days & 45 days & 72 \\
5 & 79 days & 83 days & 24 \\
& 17 days & 28 days & 20
\end{tabular}

\footnotetext{
${ }^{6}$ In July 2015, the company who ran the AF call centre, Broadcasting Support Services (BSS), went into administration upon losing the tender contract for the continued provision of this service to IBM [59] A. Rucki, "Broadcasting Support Services call centre goes into administration risking more than 100 jobs," Manchester Evening News, 24 July $2018 . \quad$ [Online]. Available: https://www.manchestereveningnews.co.uk/news/greater-manchester-news/broadcasting-support-services-callcentre-9718206, [60] Unknown, "Victims of Fraud Suffer Hotline Blow," in Mail on Sunday, ed. London, 2015. This left AF operating with a skeleton staff and had a direct impact on victims' ability to report crime within the four police forces sampled for this study. As a result, there was a sharp decrease in the volume of recorded crimes between quarter 4 of 2014-2015 and quarter 1 of 2015-2016 in this sample.
} 
\begin{tabular}{l|lll}
6 & 39 days $\quad 28$ days $\quad 25$
\end{tabular}

Table V - Summary table of time difference between consecutive reports in days, grouped by number of reports made (nreports).

\section{Crime Categories}

In addition to the previously noted difference between the Fraud and CM crime groups, differences in the extent of RV across crime categories were also found to be statistically significant $\left(\chi_{2}(1)=52.86, \mathrm{p}<0.01\right.$, Cramér's $\left.V=0.11\right)$. While the Cramér's $V$ is indicative of a small effect size, the standardised residuals in Table VI suggest that the difference is driven by the fact that reports of Advance-fee fraud and Hacking were more likely to be from repeat victims, while reports of Consumer and Other Fraud were more likely to be from one-time victims $(\mathrm{p}<0.01)$.

\begin{tabular}{|c|c|c|c|c|}
\hline Crime Category & $\begin{array}{l}\text { Victim } \\
\text { Type }\end{array}$ & $N$ & Prop & $\begin{array}{l}\text { St. } \\
\text { Residuals }\end{array}$ \\
\hline \multirow[t]{2}{*}{ Advance-fee fraud } & Once & $\begin{array}{l}190 \\
7\end{array}$ & 0.21 & $-2.95 * *$ \\
\hline & Repeat & 198 & 0.25 & $2.95 * *$ \\
\hline \multirow{2}{*}{$\begin{array}{l}\text { Card and Banking } \\
\text { fraud }\end{array}$} & Once & 445 & 0.05 & 2.43 \\
\hline & Repeat & 23 & 0.03 & -2.43 \\
\hline \multirow[t]{2}{*}{ Consumer Fraud } & Once & $\begin{array}{l}427 \\
9\end{array}$ & 0.46 & $2.85 * *$ \\
\hline & Repeat & 324 & 0.41 & $-2.85 * *$ \\
\hline \multirow[t]{2}{*}{ Hacking } & Once & 439 & 0.05 & $-9.76 * *$ \\
\hline & Repeat & 102 & 0.13 & $9.76^{* *}$ \\
\hline \multirow[t]{2}{*}{ Investment fraud } & Once & 174 & 0.02 & -1.76 \\
\hline & Repeat & 22 & 0.03 & 1.76 \\
\hline \multirow[t]{2}{*}{$\begin{array}{l}\text { Malware, } \\
\text { (D)DOS }\end{array}$} & Once & 248 & 0.03 & 1.32 \\
\hline & Repeat & 15 & 0.02 & -1.32 \\
\hline \multirow[t]{2}{*}{ Other fraud } & Once & $\begin{array}{l}148 \\
0\end{array}$ & 0.16 & $4.19 * *$ \\
\hline & Repeat & 82 & 0.1 & $-4.19 * *$ \\
\hline \multirow[t]{2}{*}{ Services fraud } & Once & 242 & 0.03 & -0.07 \\
\hline & Repeat & 21 & 0.03 & 0.07 \\
\hline
\end{tabular}

Table VI - - Number of repeat and one-time reports by crime category, proportion of total reports, along with Chisquared standardised residuals. ** indicates statistical significance at $\mathbf{p}<0.01$. 
The next aspect to be analysed concerned the sequence of crimes experienced by repeat victims. Table VII provides a matrix for the observed sequences, including the count for each combination of consecutive crimes reported by individual victims, along with row percentages and standardised residuals. Given the small numbers in some of the combinations, a number of categories were combined: the category of Malware, Virus \& (D)DOS was combined with the category Hacking; Other and Services fraud were combined into Computer Misuse (CM); and, finally, the categories of Card and Banking and Investment Fraud were also combined.

Looking across the highlighted diagonal in Table VII, it becomes apparent that in the great majority of cases, the repeat crime is of the same type as the crime that preceded it. The significant difference between the possible combinations of crime categories for consecutive reports was confirmed with a Chi-squared test $\left(\chi_{2}(16)=511.20, \mathrm{p}<0.01\right.$, Cramér's $\left.V=0.54\right)$. Furthermore, the standardised residuals in Table VII confirm that this difference is driven by the repeat victimisation being significantly more likely to be of the same type as the crime which preceded it $(\mathrm{p}<0.01)$.

\begin{tabular}{|c|c|c|c|c|c|}
\hline & $\begin{array}{l}\text { Advance- } \\
\text { fee }\end{array}$ & $\begin{array}{l}\text { Card, } \\
\text { Bank \& } \\
\text { Investment }\end{array}$ & Consumer & Hacking & Other \\
\hline \multirow[t]{3}{*}{ Advance-fee } & 66 & 7 & 23 & 3 & 13 \\
\hline & $58.93 \%$ & $6.25 \%$ & $20.54 \%$ & $2.68 \%$ & $11.61 \%$ \\
\hline & $7.54 * *$ & 0.13 & $-2.9 * *$ & $-3.8 * *$ & -0.9 \\
\hline \multirow{3}{*}{$\begin{array}{l}\text { Card, Bank } \\
\& \\
\text { Investment }\end{array}$} & 8 & 9 & 2 & 1 & 4 \\
\hline & $33.33 \%$ & $37.50 \%$ & $8.33 \%$ & $4.17 \%$ & $16.67 \%$ \\
\hline & 0.93 & $6.34 * *$ & -2.32 & -1.59 & 0.23 \\
\hline \multirow[t]{3}{*}{ Consumer } & 21 & 6 & 125 & 15 & 12 \\
\hline & $11.73 \%$ & $3.35 \%$ & $69.83 \%$ & $8.38 \%$ & $6.70 \%$ \\
\hline & $-3.36 * *$ & -1.42 & $7.13 * *$ & -3 & $-2.83^{* *}$ \\
\hline \multirow[t]{3}{*}{$C M$} & 3 & 1 & 6 & 57 & 2 \\
\hline & $4.35 \%$ & $1.45 \%$ & $8.70 \%$ & $82.61 \%$ & $2.90 \%$ \\
\hline & $-3.33 * *$ & -1.53 & $-3.89 * *$ & $12.73^{* *}$ & -2.58 \\
\hline \multirow[t]{3}{*}{ Other } & 7 & 3 & 7 & 2 & 34 \\
\hline & $13.21 \%$ & $5.66 \%$ & $13.21 \%$ & $3.77 \%$ & $64.15 \%$ \\
\hline & -1.61 & -0.09 & $-2.87 * *$ & -2.43 & $9.3 * *$ \\
\hline
\end{tabular}

Table VII - Change matrix of consecutive reports, including, for each combination of consecutive categories the count, row percentage and standardised residuals. **residual significant at the $p<0.01$ level.

\section{Part V - Discussion of Results and Implications for Crime Prevention}

This analysis revealed that a significant proportion of victims who report F\&CM are repeat victims, with $4 \%$ of victims reporting $8 \%$ of crimes. In addition, if the crime groups are 
considered separately, approximately $3 \%$ of fraud victims reported $7 \%$ of recorded frauds, while approximately $6 \%$ of $\mathrm{CM}$ victims reported $15 \%$ of CM crimes. However, this difference is likely the result of the application of HOCR. In addition, categories including Advance-fee Fraud and Hacking were associated with a higher likelihood of repeat victimisation. This is especially striking for Advance-fee Fraud as, unlike Hacking, the HOCR will favour the recording of one crime where the same individual is victimised multiple times by the same offender. For example, if a victim acquiesces to multiple requests for money by the same offender and these are reported at the same time, only one crime will be recorded. In contrast, one crime is recorded for each account/device hacked. Moreover, where victims are victimised repeatedly, this tends to be within the same general crime category. Nonetheless, it is important that individuals understand that certain crime types (e.g. Advance-fee and Investment Fraud) have in themselves varied modus operandi. Neglecting this may hinder the effectiveness of prevention advice/messaging. In addition, a statistically significant difference, albeit with a negligible effect size, was found between the proportion of RV found across the three forces, driven by a greater proportion of repeat victims in Dyfed/Powys. Given the association found between RV and older age, this likely results from the older profile of victims from Dyfed/Powys (on average 55, median 57, when the average and median for Gwent and South Wales were both 50 and 48 respectively). Nonetheless, this analysis highlights the potential of measuring RV across all forces may help identify where greater victim support resources are needed.

The overall extent of RV may be under-estimated due to the F\&CM under-reporting and the fact that arguably distinct incidents are sometimes registered as one crime. Nonetheless, these results lend strength to the argument that overall crime volumes could be reduced by targeting prevention at those likely to become repeat victims and making all victims aware of the potential for RV. While the extent of RV observed in this dataset is not of the same order of magnitudes found within other types of crime (violent crime and domestic violence in particular), identifying and targeting prevention measures at repeat victims would still help reduce the volume of $\mathrm{F} \& \mathrm{CM}$ crimes. It may also help provide a meaningful and victim-centred law enforcement response, in a context where the great majority of F\&CM crimes reported to the police are not 'actioned' in any way. By 'actioned' it is meant that the report is reviewed by the NFIB and, where applicable, referred to a police force and/or partner agency for a response including, among others, investigation or victim support. Within this sample, only $15 \%$ of all recorded crimes were actioned in some way [61]. In this context, the need to focus on prevention and protecting victims from being re-victimised is possibly the most effective crime reduction strategy. As such, the identification and response to repeat victims of F\&CM, as suggested by others in relation to other crimes [62], may provide a clear and meaningful measure of law enforcement response and performance.

This analysis suggests that male and older victims are at higher risk of becoming repeat victims, while ethnicity and proxy reports made on behalf of the victim had no effect. While this is considerably different to the typical repeat victim profile for other crime types (e.g. violent crime and domestic violence), it is in line with the profile of F\&CM victims. As such, this analysis suggests that, similarly to other crime types [17,26], the characteristics that distinguish repeat from one-time victims, are similar to those that distinguish victims from non-victims. Furthermore, in line with previous research [e.g. 46, 63] the analysis of the time-course of F\&CM RV suggests that crime prevention activities will be most effective within two weeks to a month of first victimisation. However, the scope for intervention is reduced when considering the time-course of repeats as $16 \%$ of these were recorded on the same day. 
At the same time however, this paper illustrates throughout how recording practices impact the ability to identify repeat victims. Reflecting the HMIC's [38] findings and as corroborated by Shorrock and colleagues [58] in the context of domestic violence and repeat safeguarding referrals respectively, recording practices may lead to the over-estimation of RV in the case of $\mathrm{CM}$ and its under-estimation in the case of fraud. With respect to fraud, the Modus Operandi of the crime often involves building trust with the victim over a period of time and often an escalation of intimacy and/or requests for money until the point where that trust is ultimately broken [e.g. 64, 65]. In such situations, it is likely that each incident would be recorded on the same day, but it may be questioned whether the victim experiences one instance of victimisation (over a period of time) or several. Nonetheless, even when victims report multiple crimes on the same day, there is an opportunity to establish whether they are in fact a repeat victim and therefore make appropriate support should be made available to avoid further revictimisation. Adding to previous research [61], it is thus suggested that while police records collected by AF provide a rich source of data, improving data collection so that repeat victims and patterns of RV are more easily identified would both enabled further research and aid local forces in the delivery (or facilitation) of a more victim-focused response.

Finally, identifying the factors which are associated with RV is essential to enable forces to seek to reduce RV and, as directed by the Victims' Code, provide support to repeat victims. However, if interventions are to successfully meet victims' needs, vulnerability may need to be conceptualised in broader terms, beyond individual characteristics which may or not predict likelihood of re-victimisation. In itself, being or not re-victimised says little about individuals' support needs or their ability to recover from the impact of being victimised. As such, a framework of F\&CM vulnerability is needed which goes beyond risk of re-victimisation and better accounts for and responds to victims' wider needs. However, as others have noted, current understandings of vulnerability are inconsistently deployed across police forces [14] and work is needed to identify how best 'the vulnerable' may be identified.

\section{Part VI - Conclusion}

Repeat victimisation (RV) is a 'complex phenomenon' [66] which can result from a plethora of factors. Furthermore, victimisation to $\mathrm{F} \& \mathrm{CM}$ is known to be largely under-recorded and this, along with the rules that govern the recording of crime, affects the measurement of RV. Nonetheless, even after considering the limitations associated with police recorded crime and those imposed by the linkage methodology, this analysis demonstrates that identifying and analysing patterns of RV within reported crime will produce insights of theoretical interest and of value to the planning and targeting of crime prevention activities.

Identifying RV could help target limited resources towards areas where demand for crime prevention and victim-support is greater. If there are differences in levels of repeat victimisation across England and Wales, identifying these victims would enable a better allocation of crime prevention resources. Furthermore, it could enable strategic resource allocation within each force, towards crime types where re-victimisation is more common and individuals who are most vulnerable to further victimisation. Here, repeat victims' characteristics along with the typical patterns of RV should inform prevention advice and awareness raising campaigns within communities.

At the same time, this paper has also highlighted the limitations of the RV lens. The measurement of RV is inevitably shaped by how it is defined and, in the case of this study, by recording practices. Furthermore, while useful as a crime-reduction strategy, RV should be 
understood as a much narrower concept than 'vulnerability', particularly where assessments of vulnerability are used to determine what support is made available to victims of F\&CM.

\section{Acknowledgement}

This paper is indebted to the support of the Cybercrime team at the Southern Wales Regional Organised Crime Unit and the feedback of Professor Stuart Macdonald. It is also greatly indebted to the three anonymous eCrime 2020 reviewers, whose comments were invaluable in its development.

\section{Bibliography}

[1] ONS, "Crime in England and Wales: year ending Sept 2016," in "Statistical Bulletin," Office for National Statistics, 19 January 2017 2017. Accessed: 16 March 2018. [Online]. Available: https://www.ons.gov.uk/peoplepopulationandcommunity/crimeandjustice/bulletins/cri meinenglandandwales/yearendingsept 2016

[2] ONS. Crime in England and Wales: Appendix Tables - Year Ending March 2020. [Online]. Available: https://www.ons.gov.uk/peoplepopulationandcommunity/crimeandjustice/datasets/cri meinenglandandwalesappendixtables

[3] (2016). National Cyber Security Strategy 2016-2021. [Online] Available: https:/www.gov.uk/government/uploads/system/uploads/attachment_data/file/567242 /national_cyber_security_strategy_2016.pdf

[4] HM Goverment, "Fraud Review," Office of the Attorney-General, 2006.

[5] M. Levi and J. Burrows, "Measuring the Impact of Fraud in the UK: A Conceptual and Empirical Journey," British Journal of Criminology, vol. 48, no. 3, pp. 293-318, 2008.

[6] M. Button, C. Lewis, and J. Tapley, "Fraud typologies and victims of fraud Literature review," National Fraud Authority 2009. [Online]. Available: https:/www.gov.uk/government/uploads/system/uploads/attachment_data/file/118469 /fraud-typologies.pdf

[7] M. Hall, "Supporting victims of crime in England and Wales: Local commissioning meeting local needs?," International Review of Victimology, vol. 24, no. 2, pp. 219-237, 2018/05/01 2018, doi: 10.1177/0269758017747055.

[8] J. Owen, "Concentrix: US firm brought in by City of London police to run Action Fraud helpline despite concerns," The Independent, 20 October 2015. [Online]. Available: https:/www.independent.co.uk/news/uk/home-news/concentrix-us-firm-brought-inby-city-of-london-police-to-run-action-fraud-helpline-despite-concernsa6701771.html

[9] P. Morgan-Bentley, "Fraud victims failed by police; Hotline staff trained to mislead callers; Vulnerable people labelled as morons; Workers play-fight while taking 
reports; Computer scoring system decides which cases are investigated " in The Times, 1 ed. London, 2019, pp. 1, 6-7.

[10] A. Scholes, "The scale and drivers of attrition in reported fraud and cyber crime," Home Office, London, 2018. Accessed: 11 April 2019. [Online]. Available: https://www.gov.uk/government/publications/the-scale-and-drivers-of-attrition-inreported-fraud-and-cyber-crime

[11] M. Button and C. Cross, Cyber Frauds, Scams and their Victims. Taylor \& Francis, 2017.

[12] (2015). Code of Practice for Victims of Crime. [Online] Available: https://www.cps.gov.uk/legal/assets/uploads/files/OD_000049.pdf

[13] K. Pease, D. Ignatans, and L. Batty, "Whatever happened to repeat victimisation?," Crime Prevention and Community Safety, vol. 20, no. 4, pp. 256-267, 2018.

[14] M. Skidmore, J. Goldstraw-White, and M. Gill, "Vulnerability as a driver of the police response to fraud," Journal of Criminological Research, Policy and Practice, (in press).

[15] V. Braun and V. Clarke, "Thematic Analysis," in APA handbook of research methods in psychology, vol. 2, H. Cooper Ed., no. Research designs: Quantitative, qualitative, neuropsychological, and biological.). Washington DC: American Psychological Association, 2012.

[16] G. Farrell, "Multiple Victimisation: Its Extent and Significance," International Review of Victimology, vol. 2, no. 2, pp. 85-102, 1992/01/01 1992, doi: $10.1177 / 026975809200200201$.

[17] D. Ignatans and K. Pease, "Taking Crime Seriously: Playing the Weighting Game," Policing: A Journal of Policy and Practice, vol. 10, no. 3, pp. 184-193, 2016, doi: 10.1093/police/pav029.

[18] A. Sampson and C. Phillips, "Reducing Repeat Racial Victimisation on an East London Estate," in "Crime Detection and Prevention Series," London, 1991. Accessed: 5 February $2020 . \quad$ [Online]. Available: http://library.college.police.uk/docs/hopolicers/fcdps67.pdf

[19] A. J. Brimicombe, "Mining Police-Recorded Offence and Incident Data to Inform a Definition of Repeat Domestic Abuse Victimization for Statistical Reporting," Policing, p. paw025, 2016, doi: 10.1093/police/paw025.

[20] N. Polvi, T. Looman, C. Humphries, and K. Pease, "The Time Course of Repeat Burglary Victimization," The British Journal of Criminology, vol. 31, no. 4, pp. 411414, 1991, doi: 10.1093/oxfordjournals.bjc.a048138.

[21] S. D. Johnson, "Repeat Burglary Victimisation: A Tale of Two Theories," Journal of Experimental Criminology \& Public Policy, vol. 4, no. 3, pp. 215-240, 2008.

[22] G. Farrell and K. Pease, "One Bitten, Twice Bitten: Reapeat Victimisation and its Implications for Crime Prevention," Home Office Police Research Group, 1993.

[23] R. Sparks, H. Genn, and D. Dodd, Surveying Victims. London: Wiley, 1977.

[24] R. Sparks, "Multiple Victimisation: Evidence, Theory and Future Research," Journal of Criminal Law and Criminology, vol. 72, no. 2, pp. 762-778, 1981. [Online]. Available: 
https://scholarlycommons.law.northwestern.edu/cgi/viewcontent.cgi?article=6239\&co ntext $=$ jclc.

[25] M. Hindelang, M. R. Gottfredson, and J. Garofalo, Victims of Personal Crime: an Empirical Foundation for a Theory of Personal Victimisation. Cambridge, Mass.: Ballinger, 1978.

[26] D. Ignatans and K. Pease, "Distributive Justice and the Crime Drop," in The Criminal Act: The Role and Influence of Routine Activity Theory, M. A. Andresen and G. Farrell Eds. London: Palgrave Macmillan, 2015, pp. 77-87.

[27] M. T. Whitty, "Predicting susceptibility to cyber-fraud victimhood," Journal of Financial Crime, vol. 26, no. 1, pp. 277-292, 2019.

[28] C. D. Hawkins, "Repeat Victimisation in Online Fraud: The 'ideal' and 'real' victims of fraud," $\mathrm{PhD}$, School of Media, Communication and Sociology, University of Leicester, Leicester, $2019 . \quad$ [Online]. Available: https://leicester.figshare.com/articles/Repeat_Victimisation_in_Online_Fraud The id eal_and_real_victims of fraud/10319300/1

[29] W. van der Wagen and W. Pieters, "The hybrid victim: Re-conceptualizing high-tech cyber victimization through actor-network theory," European Journal of Criminology, vol. 17, no. 4, pp. 480-497, 2020/07/01 2020, doi: 10.1177/1477370818812016.

[30] ONS, "Improving estimates of repeat victimisation derived from the Crime Survey for England and Wales," Titchfield, 19 October 2017 2017. Accessed: 12 February 2020. [Online].

Available: https://www.ons.gov.uk/peoplepopulationandcommunity/crimeandjustice/methodolog ies/improvingestimatesofrepeatvictimisationderivedfromthecrimesurveyforenglandan dwales

[31] ONS. Crime in England and Wales: Annual Trend and Demographic Tables - Year Ending March $2020 . \quad$ [Online]. Available: https://www.ons.gov.uk/peoplepopulationandcommunity/crimeandjustice/datasets/cri meinenglandandwalesannualtrendanddemographictables

[32] ONS, "User guide to crime statistics for England and Wales," ed. Titchfield: Office for National Statistics, 2020, pp. 1-138.

[33] R. Barr and K. Pease, "A Place for Every Crime and Every Crime in its Place," in The Distribution of Crime, D. Herbert, D. Evans, and N. Fyfe Eds. Gower: Aldershot, 1991.

[34] A. Sidebottom, "Repeat Burglary Victimization in Malawi and the Influence of Housing Type and Area-Level Influence.," Security Journal, vol. 25, no. 3, pp. 265281, 2012.

[35] G. Farrell, A. Tseloni, and K. Pease, "Repeat Victimization in the ICVS and the NCVS," Crime Prevention and Community Safety, vol. 7, no. 3, pp. 7-18, 2005/07/01 2005, doi: 10.1057/palgrave.cpcs.8140221.

[36] H. Genn, " Multiple victimisation," in Victims of Crime: A New Deal?, M. Maguire and J. Pointing Eds. Milton Keynes: Open University Press, 1988.

[37] G. Farrell, "Preventing Repeat Victimization," Crime and Justice, vol. 19, pp. 469-534, 1995. 
[38] HMIC, "Increasingly Everyone's Business: A Progress Report on the Police Response to Domestic Abuse," London, 2015.

[39] ONS. Significance testing for proportion of adults who were victims of fraud and computer misuse by personal and household characteristics, year ending March 2019 CSEW. [Online].

Available: https://www.ons.gov.uk/peoplepopulationandcommunity/crimeandjustice/adhocs/112 19 significancetestingforproportionofadultswhowerevictimsoffraudandcomputermisus ebypersonalandhouseholdcharacteristicsyearendingmarch2019csew

[40] M. T. Whitty, "Mass-marketing fraud: a growing concern," IEEE Security and Privacy, vol. 13, no. 4, pp. 84-87, 2015.

[41] S. Walby, J. Towers, and B. Francis, "Is Violent Crime Increasing or Decreasing? A New Methodology to Measure Repeat Attacks Making Visible the Significance of Gender and Domestic Relations," British Journal of Criminology, vol. 56, no. 6, pp. 1203-1234, 2016.

[Online].

Available: http://bjc.oxfordjournals.org/content/early/2016/01/31/bjc.azv131.abstractN2 - The fall in the rate of violent crime has stopped. This is a finding of an investigation using the Crime Survey for England and Wales, 1994-2014, and an improved methodology to include the experiences of high-frequency victims. The cap on the number of crimes included has been removed. We prevent overall volatility from rising by using threeyear moving averages and regression techniques that take account of all the data points rather than point to point analysis. The difference between our findings and official statistics is driven by violent crime committed against women and by domestic perpetrators. The timing of the turning point in the trajectory of violent crime corresponds with the economic crisis in 2008/09.

[42] A. Tseloni and K. Pease, "Repeat Personal Victimization. 'Boosts' or 'Flags'?," The British Journal of Criminology, vol. 43, no. 1, pp. 196-212, 2003, doi: 10.1093/bjc/43.1.196.

[43] A. Trickett, D. Osborn, J. Seymour, and K. Pease, "What is Different About High Crime Areas?," British Journal of Criminology, vol. 32, no. 1, pp. 81-89, 1992.

[44] A. J. Reiss, "Victim proneness in repeat victimisation by type of crime," in "Indicators of Crime and Criminal Justice: Quantitative Studies," Bureau of Justice Statistics, Washington, 1980.

[45] N. Polvi, T. Looman, C. Humphries, and K. Pease, "Repeat Break-and-Enter Victimization: Time Course and Crime Prevention Opportunity," Journal of Police Science and Administration, vol. 17, no. 1, pp. 8-11, 1990.

[46] S. D. Moitra and S. L. Konda, "An Empirical Investigation of Network Attacks on Computer Systems," Computers and Security, vol. 23, no. 1, pp. 43-51, 2004.

[47] Niche Techonology. "Who We Serve." https://nicherms.com/who-we-serve/ (accessed 4 June 2019.

[48] C. Newschaffer, ""Administrative Data"," in Encyclopedia of Epidemiology, B. Sarah and M. Louise-Anne, Eds., ed: Sage Publications, Inc, 2008, pp. 4-6.

[49] J. Flatley, "The measurement of fraud and cyber-crime and their implications for crime statistics," in "Report to the Crime Statistics Advisory Committee," Office for National Statistics (ONS), 2013. 
[50] T. Hope, J. Bryan, A. Trickett, and D. R. Osborn, "The Phenomena of Multiple Victimization. The Relationship between Personal and Property Crime Risk," The British Journal of Criminology, vol. 41, no. 4, pp. 595-617, 2001.

[51] M. Sariyar and A. Borg, "The RecordLinkage Package: Detecting Errors in Data," The $R$ Journal, vol. 2, no. 2, pp. 61-67, 2010. [Online]. Available: https://journal.rproject.org/archive/2010-2/RJournal_2010-2_Sariyar+Borg.pdf.

[52] Record Linkage Functions for Linking and Deduplicating Data Sets. (2020). Accessed: 3 June 2020. [Online]. Available: https://cran.rproject.org/web/packages/RecordLinkage/RecordLinkage.pdf

[53] P. Christen and K. Goiser, "Quality and Complexity Measures for Data Linkage and Deduplication," in Quality Measures in Data Mining, F. J. Guillet and H. J. Hamilton Eds. Berlin: Springer, 2007, pp. 127-151.

[54] (2020). Home Office Counting Rules For Recorded Crime: Fraud \& Computer Misuse. [Online]

Available: https://assets.publishing.service.gov.uk/government/uploads/system/uploads/attachme nt data/file/694449/count-fraud-apr-2018.pdf

[55] J. Cohen, Statistical power analysis for the behavioral sciences, 2nd. ed. New York: Lawrence Erlbaum Associates, 1988.

[56] L. M. Rea and R. A. Parker, Designing and conducting survey research: a comprehensive guide, 4th ed. San Francisco, CA: Wiley, 2014.

[57] C. Cross, "'They're Very Lonely': Understanding the Fraud Victimisation of Seniors," International Journal for Crime, Justice and Social Democracy, vol. 5, no. 4, pp. 6075, 2016.

[58] S. Shorrock, M. A. McManus, and S. Kirby, "Profile of repeat victimisation within multi-agency referrals," International Review of Victimology, vol. online first, pp. 1-12, 2020, doi: 10.1177/0269758020902890.

[59] A. Rucki, "Broadcasting Support Services call centre goes into administration risking more than 100 jobs," Manchester Evening News, 24 July 2018. [Online]. Available: https://www.manchestereveningnews.co.uk/news/greater-manchesternews/broadcasting-support-services-call-centre-9718206

[60] Unknown, "Victims of Fraud Suffer Hotline Blow," in Mail on Sunday, ed. London, 2015.

[61] S. Correia, "Responding to victimisation in a digital world: a case study of fraud and computer," Crime Science, vol. 8, no. 4, 2019, doi: 10.1186/s40163-019-0099-7.

[62] K. Pease, D. Ignatans, and L. Batty, "Whatever happened to repeat victimisation?," Crime Prevention and Community Safety, vol. 20, pp. 256-267, 2018.

[63] A. Sagovsky and S. D. Johnson, "When does repeat burglary victimisation occur?," Australian and New Zealand Journal of Criminology vol. 40, no. 1, pp. 1-26, 2007.

[64] M. Button, C. M. Nicholls, J. Kerr, and R. Owen, "Online frauds: Learning from victims why they fall for these scams," Australian \& New Zealand

Journal of Criminology, vol. 47, no. 3, pp. 391-408, 2014. 
[65] C. Cross, M. Dragiewicz, and K. Richards, "Understanding Romance Fraud: Insights From Domestic Violence Research," The British Journal of Criminology, vol. 58, no. 6, pp. 1303-1322, 2018, doi: 10.1093/bjc/azy005.

[66] J. J. Turanovic and T. C. Pratt, "'Can't stop, won't stop': Self-control, risky lifestyles, and repeat victimiza tion," Journal of Quantitative Criminology, vol. 30, no. 1, pp. 29$56,2014$. 